\title{
Photocatalytic Degradation of Azure A Using N-Doped Zinc Oxide
}

\author{
Priya Rathore*, Rakshit Ameta, Sanyogita Sharma \\ Department of Chemistry, PAHER University, Udaipur, India \\ Email: "priyarathore251286@gmail.com
}

Received 16 October 2015; accepted 22 November 2015; published 25 November 2015

Copyright (C) 2015 by authors and Scientific Research Publishing Inc.

This work is licensed under the Creative Commons Attribution International License (CC BY).

http://creativecommons.org/licenses/by/4.0/

(c) (i) Open Access

\begin{abstract}
Photocatalysis has been predicted as a promising technology for waste water treatment. N-doped zinc oxide has been used as an effective catalyst for carrying out number of chemical reactions, but limited work has been reported on use of $\mathrm{N}$-doped $\mathrm{ZnO}$ as photocatalyst. In the present work, the photocatalytic degradation of Azure A was carried out in the presence of $\mathrm{N}$-doped zinc oxide and the progress of the reaction was observed spectrophotometrically. The morphologies and structures of the as-synthesized nanomaterials were investigated by using FT-IR and DRS techniques. On the basis of observations, a tentative mechanism has been proposed for the photocatalytic degradation of dye.
\end{abstract}

\section{Keywords}

Azure A, Nanoparticles, N-Doped Zinc Oxide, Photocatalysis

\section{Introduction}

Water pollution is a serious threat for the environment. The sources of pollutants are generally textile and chemical industries using organic dyes. Therefore, methods for treatments of such polluted water are required. The waste water flows in the drains corrodes and incrusts the sewerage pipes. If allowed to flow in drains and rivers, it also effects the quality of drinking water in hand pumps making it unfit for human consumption. It leads to leakage in drains increasing their maintenance cost. Such polluted water provides breeding ground for bacteria and virus. All the organic materials present in the wastewater from a textile industry have a great concern in water treatment.

Dye degradation is a process, in which the large dye molecules are broken into smaller molecules like water, $\mathrm{CO}_{2}$ and mineral byproducts. The waste water that the industry releases contains some amount of these dye mo-

${ }^{*}$ Corresponding author. 
lecules, which cause water pollution because many of them are non-reactive towards light, acids, bases and $\mathrm{O}_{2}$. So the colour of the material becomes permanent.

Photocatalysis is the addition of light to semiconductor generally metal oxides and sulphides, which results in moving electrons from valence band to conduction band. The electron hole pairs formed will react with $\mathrm{O}_{2}$ and $\mathrm{H}_{2} \mathrm{O}$ molecules to form superoxides anions and ${ }^{\circ} \mathrm{OH}$ radical, which have more oxidizing and reducing properties for the dye compounds used in many industries. Due to the importance of photocatalysis, researches are applying photocatalytic decomposition process to degrade the organic pollutants of industrial waste water before discharging it in mainstream.

Various metal oxide semiconductors, such as $\mathrm{TiO}_{2}, \mathrm{ZnO}, \mathrm{WO}_{3}$ and $\mathrm{SnO}_{2}$, have been studied and applied as photocatalysts. Among them, $\mathrm{TiO}_{2}$ is considered the most efficient photocatalyst due to its abundant availability, cost-effectiveness and chemical stability. However, recent researches have shown that $\mathrm{ZnO}$ can be used as a more efficient photocatalyst compared with $\mathrm{TiO}_{2}$ [1] [2]. An important characteristic is that $\mathrm{ZnO}$ contains various intrinsic defects. Introducing defects into $\mathrm{ZnO}$ structure can not only narrow the band gap to increase the solar light harvesting capability, but also bring many split energy gaps to set up a possible catalytic systems, which sense and shoot environmental contaminants [3] [4].

Kothari et al. [5] reported the photocatalytic degradation of evans blue, an azo dye and its mixture with amaranth in presence of $\mathrm{ZnO}$. Photocatalytic mineralization of methylene blue using buoyant $\mathrm{TiO}_{2}$-coated polystyrene beads was observed by Fabiyi and Skelton [6]. Ameta et al. [7] have used Iron(III) oxide for photobleaching of methylene blue, crystal violet and malachite green. Punjabi et al. [8] observed the reduction of Congo red by ascorbic acid and EDTA over CdS as a photocatalyst. Increase in photocatalytic activity of $\mathrm{ZnO}$ was reported by Benjamin et al. [9] by coating it with some natural pigments.

Egzar et al. [10] carried out the photocatalytic degradation of aniline blue dye using different semiconductors such as $\mathrm{ZnO}, \mathrm{ZnS}$ and $\mathrm{SnO}_{2}$. Photocatalytic degradation of various dyes i.e. orange-II, orange-G, Congo red, indigo carmine, crystal violet and malachite green has been reported by Hachem et al. [11]. Pare et al. [12] carried out the photocatalytic degradation of lissamine fast yellow in the aqueous suspension of $\mathrm{ZnO}$ under artificial light. The photocatalytic bleaching of eosin using $\mathrm{ZnO}$ and effect of surface charge was investigated by Vyas et al. [13]. Ameta et al. [14] carried out the photodegradation of naphthol green B dye using antimony trisulphide as a heterogeneous catalyst.

Attia [15] has reported the photocatalytic oxidation of iodide ion in the aqueous suspension of zinc oxide and its sensitization with riboflavin where as Habibi and Askari [16] used Mn-doped ZnOnanocomposite thin film coated on glass by a simple spin-coating method to degradeanazo textile dye. Ahmad et al. [17] synthesized $\mathrm{Al}$-doped $\mathrm{ZnO}$ photocatalysts with different $\mathrm{Al}$ concentrations (0.5 - $6.0 \mathrm{~mol} \%)$. Their results showed that this photocatalyst doped with $4.0 \mathrm{~mol} \% \mathrm{Al}$ exhibited five times enhanced photocatalytic activity compared to pure ZnO. Peng et al. [18] have prepared Ag-sensitized $\mathrm{ZnO}$ and compared the activity of $\mathrm{ZnO}$ and $\mathrm{Ag} / \mathrm{ZnO}$. They found that $\mathrm{Ag} / \mathrm{ZnO}$ showed better photocatalytic performance under simulated solar light for the degradation of phenol and methyl orange.

\section{Material and Method}

\subsection{Preparation of $\mathrm{ZnO}$ Nanoparticles}

Zinc acetate dihydrate $\left[\mathrm{Zn}\left(\mathrm{CH}_{3} \mathrm{COO}\right)_{2} \cdot 2 \mathrm{H}_{2} \mathrm{O}\right](131.6 \mathrm{~g})$ was added to $3 \mathrm{~L}$ of deionized waterunder vigorous stirring till homogeneous solution was obtained. Then $172.8 \mathrm{~g}$ of sodium dodecyl sulphate (SDS) and $0.2 \mathrm{M}$ of sodium hydroxide were added into the above solution under continuous stirring till $\mathrm{pH}$ value reached 12 and heated at $160^{\circ} \mathrm{C}$ for $14 \mathrm{~h}$ in an oven. The precipitates were recovered by centrifugation and washed with deionized water and ethanol several times [19]. The product was dried at $60^{\circ} \mathrm{C}$ for $3 \mathrm{~h}$ and labelled as uncalcined zinc oxide (Znc). A portion of this product ( $10 \mathrm{~g} \mathrm{Znc}$ ) was calcined at $400^{\circ} \mathrm{C}$ for $4 \mathrm{~h}$, cooled to room temperature, ground in agate mortarand labelled as calcined zinc oxide $(\mathrm{Zc})$. At the end of the reaction, sodium dodecyl sulfate (SDS) and $\mathrm{CH}_{3} \mathrm{COONa}$ were eliminated during washing of $\mathrm{Zn}(\mathrm{OH})_{2}$. The final yield of $\mathrm{ZnO}$ was $90 \%$.

\subsection{Preparation of Nitrogen-Doped ZnO}

The $\mathrm{N}$-doped $\mathrm{ZnO}$ was synthesized in a solvent free reaction. $20 \mathrm{~g}$ of uncalcined zinc oxide was added to $40 \mathrm{~g}$ of urea and grinded in an agate mortar. The mixture was calcined in a ceramiccrucible at $400^{\circ} \mathrm{C}$ for $4 \mathrm{~h}$ and cooled [20]. The product was ground to fine powder and labeled as nitrogen-doped zinc oxide (NZ). 


\section{Characterization of Compound}

\subsection{Fourier Transform Infrared Spectroscopy (FT-IR)}

FT-IR analysis of both the prepared samples were done using Bruker FT-IR. FT-IR results showed an absorption peak at $450-540 \mathrm{~cm}^{-1}$ and $1562 \mathrm{~cm}^{-1}$, which confirmed the presence of ZnO nanoparticles [21]-[24]; another intense, broad peak near $3360 \mathrm{~cm}^{-1}$ represented the hydrogen bonded O-H stretching vibration [25]. Strong peaks obtained at $1562 \mathrm{~cm}^{-1}$ and at $1404 \mathrm{~cm}^{-1}$ confirmed the presence of hydrolyzed particles.

\subsection{Diffuse Reflectance Spectroscopy (DRS)}

As-prepared pure $\mathrm{ZnO}$ and N-doped ZnO were analyzed by DRS to know the band gap. DRS analysis was done using UV Vis spectrophotometer with DRS, Model UV vis-3000+, Lab-India. The samples were run with the mixture of dry $\mathrm{BaSO}_{4}$ at room temperature. It was found in DRS results that the band gap of pure ZnO was 3.4 $\mathrm{eV}$ and it was $3.2 \mathrm{eV}$ for $\mathrm{N}$-doped $\mathrm{ZnO}$. It confirms the reduction of band gap by doping $\mathrm{ZnO}$ with nitrogen, as a consequence $\mathrm{N}$-doped $\mathrm{ZnO}$ was found better in compare to pure $\mathrm{ZnO}$ for degradation of Azure A.

\subsection{Scanning Electron Microscope (SEM)}

SEM were recorded on SEM Jeol Japan make, 5610LV model of undoped as well as nitrogen doped Zinc Oxide (Figure 1 and Figure 2). It is clearly from micrograph that undoped Zinc Oxide was larger in size as compared to nitrogen doped Zinc Oxide. These, it may be concluded that nitrogen doping of Zinc Oxide reduces its particle size. It was substainated by XRD data where particle size of undoped $\mathrm{ZnO}$ is $45.31 \mathrm{~nm}$ and it was reduced to $29.16 \mathrm{~nm}$ after doping.

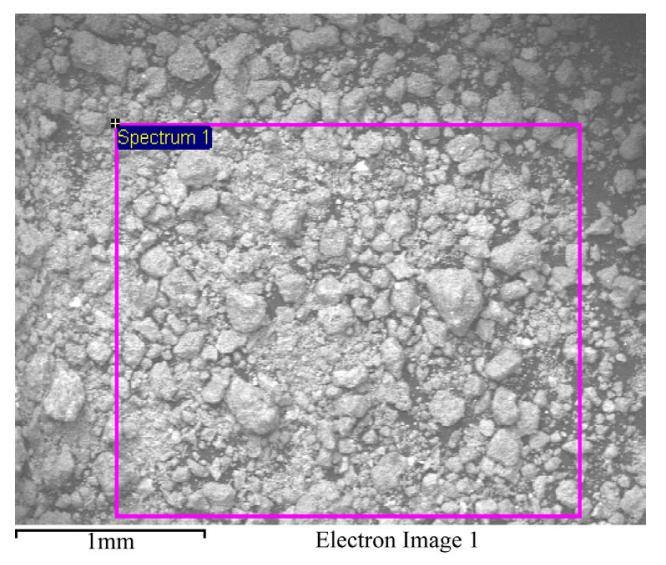

Figure 1. SEM undoped $\mathrm{ZnO}$.

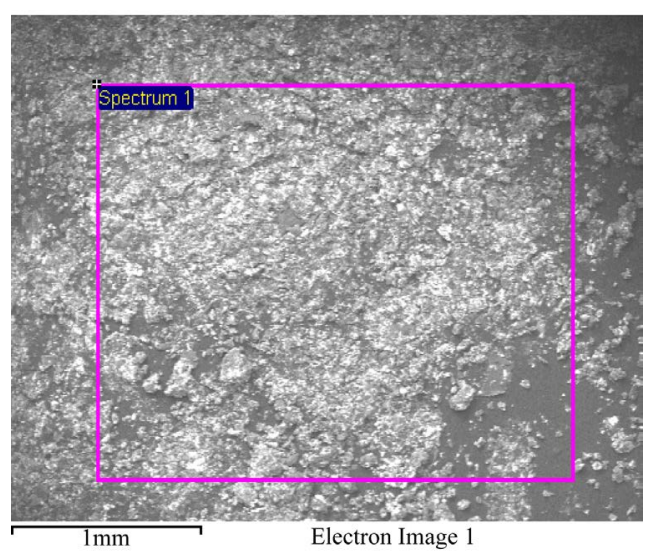

Figure 2. SEM nitrogen doped $\mathrm{ZnO}$. 


\section{Experiment}

Azure A dye and semiconducting N-doped zinc oxide powder were used in the present investigation of AR grade. All the solutions were prepared in doubly distilled water. The photocatalytic degradation of the dye was observed by taking dye solution and zinc oxide together. Irradiation was carried out by keeping the whole assembly exposed to a $200 \mathrm{~W}$ Tungsten lamp (Philips; light intensity $=50.0 \mathrm{~mW} \cdot \mathrm{cm}^{-2}$ ). The intensity of light at various distances from the lamp was measured with the help of a solarimeter. The $\mathrm{pH}$ of the solutions was measured with the help of digital $\mathrm{pH}$-meter.

$0.02918 \mathrm{~g}$ of Azure A was dissolved in $100 \mathrm{~mL}$ of doubly distilled water to prepare their $1.0 \times 10^{-3} \mathrm{M}$ solution, which was used as stock solution. The stock solution was further diluted as and when required. The absorbance of the dye solution were determined with the help of a spectrophotometer at $\lambda_{\max }=620 \mathrm{~nm}$ for Azure A. The progress of reaction was observed by measuring absorbance of the reaction mixture at regular time interval during exposure. Decreasing trend of absorbance showed that dye was degraded during this process.

A decrease in absorbance of Azure A solution was observed with increasing time of exposure. A plot of $1+$ $\log \mathrm{A}$ against time was found linear for pure $\mathrm{ZnO}$ and nitrogen doped $\mathrm{ZnO}$, which indicates that the degradation of Azure A follows pseudo-first order kinetics. The rate constant was measured with the help of Equation (1).

$$
\mathrm{k}=2.303 \times \text { slope }
$$

\subsection{Azure A}

Azure $A$ is an organic compound with the chemical formula $\mathrm{C}_{14} \mathrm{H}_{14} \mathrm{ClN}_{3} \mathrm{~S}$ (Figure 3). It is a light blue to dark blue dye. It is used for screening test for mucopolysaccharides. It is also known as Giemsa stain, Azure A chloride and dimethylthionine.

\begin{tabular}{cc}
\hline IUPAC name & (7-Amino-8-methyl-phenothiazin-3-ylidene)-dimethyl-ammoniumchloride \\
Molecular formula & $\mathrm{C}_{14} \mathrm{H}_{14} \mathrm{ClN}_{3} \mathrm{~S}$ \\
Molecular weight & $291.80 \mathrm{~g} \cdot \mathrm{mol}^{-1}$ \\
Appearance & Green to dark brown powder \\
Solubility & Water \\
\hline
\end{tabular}

\section{Results and Discussion}

Various factors, which affect degradation of Azure A dye have been studied to get the condition for optimum degradation rate.

\subsection{Effect of $\mathrm{pH}$}

The effect of $\mathrm{pH}$ on the rate of degradation of $\mathrm{N}$-doped $\mathrm{ZnO}$ was investigated in the pH range 6.0 to 10.0. The results are reported graphically in Figure 4.

[Azure A] $=1.6 \times 10^{-5} \mathrm{M}, \mathrm{N}$-doped $\mathrm{ZnO}=0.10$, Light intensity $=60.0 \mathrm{~mW} \cdot \mathrm{cm}^{-2}$.

It has been observed that the rate of photocatalytic degradation of Azure A increases as $\mathrm{pH}$ was increased and it attained optimum value at $\mathrm{pH}$ 8.0. The rate was decreased when $\mathrm{pH}$ of the dye solution was further increased. It may be due to the fact that on increasing the $\mathrm{pH}$ of the solution, there is an attraction between cationic dye molecule and negatively charged ${ }^{-} \mathrm{OH}$ ions. But, at higher $\mathrm{pH}$, the cationic dye molecules convert into neutral form and hence, there is less attraction between neutral dye molecule and negatively charged surface of semiconductor. As a result, the rate was retarded.

\subsection{Effect of Azure A Concentration}

The effect of dye concentration was observed by taking different concentrations of Azure A. The results are shown in Figure 5.

$$
\mathrm{pH}=8.0, \mathrm{~N} \text {-doped } \mathrm{ZnO}=0.10 \mathrm{~g} \text {, Light intensity }=60.0 \mathrm{~mW} \cdot \mathrm{cm}^{-2} \text {. }
$$




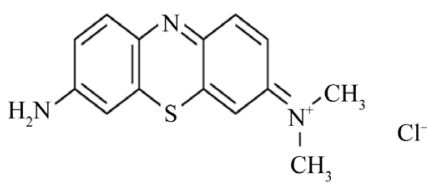

Figure 3. Structure of Azure A.

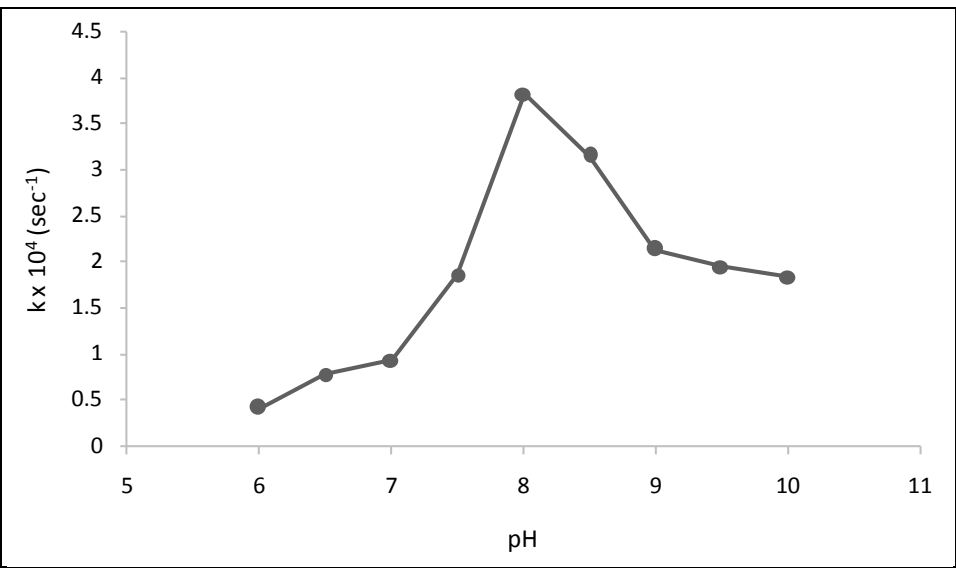

Figure 4. Effect of pH.

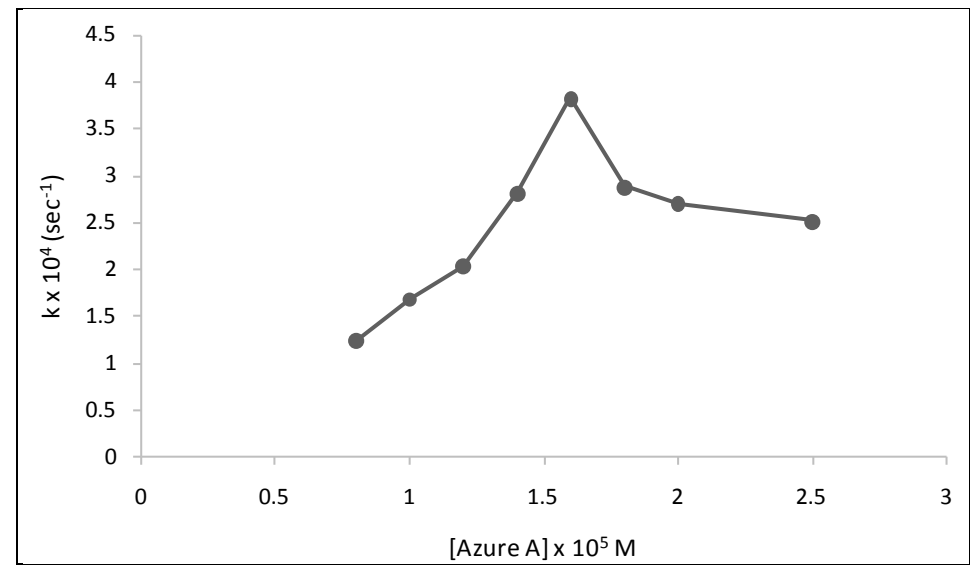

Figure 5. Effect of Azure A concentration.

It was observed that the rate of photocatalytic degradation of dye increases on increasing the concentration of Azure A upto $1.60 \times 10^{-5} \mathrm{M}$. It may be attributed to the fact that as the concentration of the Azure A was increased, more dye molecules were available for excitation and consecutive energy/electron transfer and hence, an increase in the rate of degradation of the dye was observed. There was a decrease in degradation rate on increasing the concentration of dye above $1.6 \times 10^{-5} \mathrm{M}$. This may be due to the fact that after a particular concentration, the dye may start acting as an internal filter and it will not permit the sufficient light intensity to reach the surface of the photocatalyst at the bottom of reaction vessel.

\subsection{Effect of Amount of Semiconductor}

The amount of semiconductor may also affect the degradation of dye and hence, different amounts of N-doped $\mathrm{ZnO}$ were used. The results are reported in Figure 6.

$\mathrm{pH}=8.0,[$ Azure A $]=1.6 \times 10^{-5} \mathrm{M}$, Light intensity $=60.0 \mathrm{~mW} \cdot \mathrm{cm}^{-2}$.

The rate of reaction was found to increase on increasing the amount of semiconductor, $\mathrm{N}$-doped zinc oxide. The rate of degradation reached to its optimum value at $0.10 \mathrm{~g}$ of the photocatalyst, because as the amount of the 


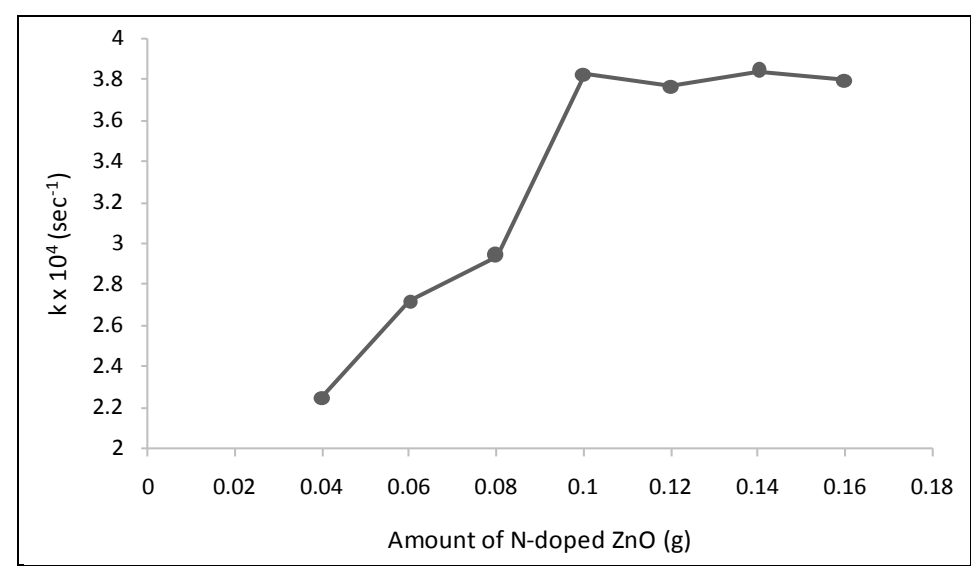

Figure 6. Effect of amount of N-doped $\mathrm{ZnO}$.

semiconductor was increased, it provides more exposed surface area for degradation of dye molecules. Beyond $0.10 \mathrm{~g}$, the rate of reaction becomes almost constant. After a particular value $(0.10 \mathrm{~g})$, an increase in the amount of semiconductor will only increase the thickness of layer of the semiconductor and not its exposed surface area. This was confirmed by taking reaction vessels of different sizes. It was observed that this point of saturation was shifted to a higher value for vessels of larger volumes while a reverse trend was observed for vessels of smaller capacities.

\subsection{Effect of Light Intensity}

The effect of light intensity on the photocatalytic degradation of Azure A was also investigated. The light intensity was varied by changing the distance between the light source and the exposed surface area of semiconductor. The results are given in Figure 7.

$$
\mathrm{pH}=8.0 \text {, [Azure A] }=1.6 \times 10^{-5} \mathrm{M}, \mathrm{N} \text {-doped } \mathrm{ZnO}=0.10 \mathrm{~g} \text {. }
$$

These data indicate that photocatalytic degradation of Azure A was enhanced with the increase in intensity of light, because an increase in the light intensity will increase the number of photons striking per unit area per unit time of photocatalyst surface. There was a slight decrease in the rate of reaction as the intensity of light was increased beyond $60.0 \mathrm{~mW} \cdot \mathrm{cm}^{-2}$.

\subsection{A Typical Run}

After keeping the values of the above parameters constant for maximum rate constant, a typical run was observed for the photocatalytical degradation of the dye. The results are shown in Table 1 and graphically presented in Figure 8. Here, a comparative observation was made for pure $\mathrm{ZnO}$ and $\mathrm{N}$-doped $\mathrm{ZnO}$, which confirms that the rate was almost six times increased in the case of $\mathrm{N}$-doped $\mathrm{ZnO}$ in compare to pure $\mathrm{ZnO}$.

\section{Mechanism}

On the basis of above observations, a tentative mechanism is proposed for the photocatalytic degradation of Azure A using N-doped $\mathrm{ZnO}$ semiconductor.

$$
\begin{aligned}
& { }^{1} \mathrm{Dye}_{0} \rightarrow{ }^{1} \mathrm{Dye}_{1} \text { (Singlet excited state) } \\
& { }^{1} \mathrm{Dye}_{1} \rightarrow{ }^{3} \mathrm{Dye}_{1} \text { (Triplet excited state) } \\
& \mathrm{SC} \rightarrow \mathrm{e}^{-}(\mathrm{CB})+\mathrm{h}^{+} \text {(VB) or } \mathrm{SC}^{*} \\
& \mathrm{~h}^{+}+{ }^{-} \mathrm{OH} \rightarrow{ }^{\circ} \mathrm{OH} \\
& \mathrm{HO}^{\circ}+{ }^{3} \mathrm{Dye}_{1} \rightarrow \text { Leuco dye } \\
& \text { Leuco dye } \rightarrow \text { Product }
\end{aligned}
$$

Azure A absorbs radiations of suitable wavelength and gives rise to its excited singlet state. Then it undergoes intersystem crossing (ISC) to give the triplet state of the dyes. On the other hand, the semi-conducting N-doped $\mathrm{ZnO}$ utilizes the radiant energy to excite its electron from valence band to the conduction band; thus, leaving behind a hole. This hole abstracts an electron from $\mathrm{OH}^{-}$ions to generate ${ }^{\circ} \mathrm{OH}$ radicals. These radicals further 


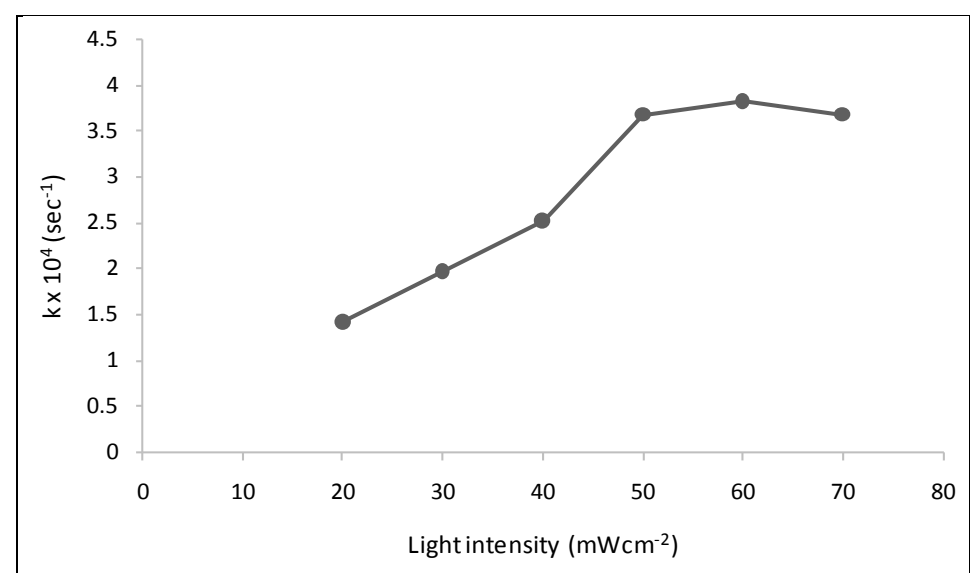

Figure 7. Effect of light intensity.

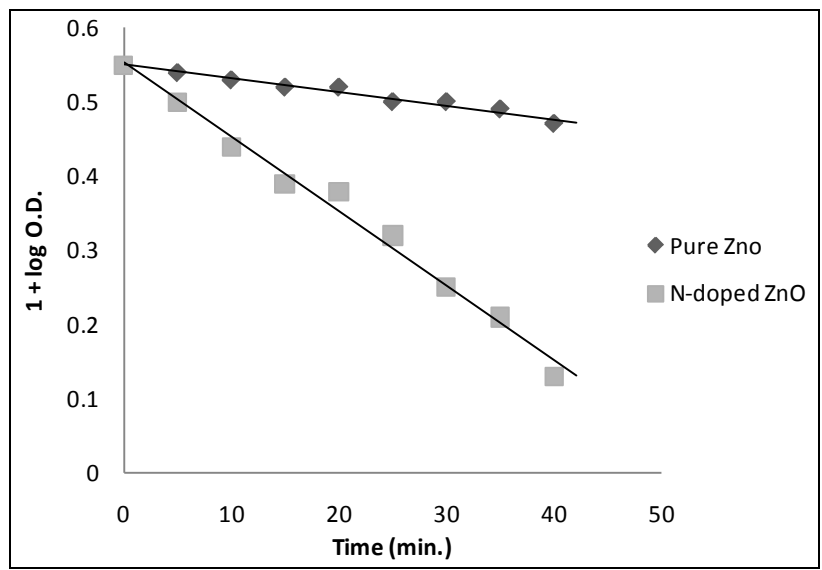

Figure 8. A typical run.

Table 1. A typical run.

\begin{tabular}{ccccc}
\hline Time (min.) & Pure ZnO (O.D.) & 1 + log O.D. & N-doped ZnO (O.D.) & 1 + log O.D. \\
\hline 0 & 0.356 & 0.55 & 0.356 & 0.55 \\
5 & 0.347 & 0.54 & 0.318 & 0.50 \\
10 & 0.339 & 0.53 & 0.278 & 0.44 \\
15 & 0.337 & 0.52 & 0.249 & 0.39 \\
20 & 0.333 & 0.52 & 0.241 & 0.38 \\
25 & 0.322 & 0.50 & 0.213 & 0.25 \\
30 & 0.317 & 0.50 & 0.178 & 0.21 \\
45 & 0.300 & 0.49 & 0.163 & 0.138 \\
\hline
\end{tabular}

$\mathrm{pH}=8.0$, [Azure A] $=1.6 \times 10^{-5} \mathrm{M}, \mathrm{N}-$ Doped $\mathrm{ZnO}=0.10 \mathrm{~g}$, Light intensity $=60 \mathrm{~mW} \cdot \mathrm{cm}^{-2}$; Rate constant $(\mathrm{k})$ for Pure $\mathrm{ZnO}=0.60 \times 10^{-4} \mathrm{sec}^{-1}$ and for $\mathrm{N}$-doped $\mathrm{ZnO}=3.83 \times 10^{-4} \mathrm{sec}^{-1}$.

oxidize the Azure A dye to its leuco form, which may ultimately degrade to products. The participation of ${ }^{\circ} \mathrm{OH}$ radicals as an active oxidizing species was confirmed by using hydroxyl radical scavenger 2-propanol, where the rate of degradation was drastically reduced. 


\section{Conclusion}

Nitrogen doped zinc oxide was prepared by precipitation method by doping pure ZnO with urea and further the as-prepared samples were characterized by FT-IR, DRS and SEM techniques. Different rate affecting parameters like $\mathrm{pH}$, dye concentrations, catalyst amount and light intensity were studied for the dye degradation. The observations revealed that Azure A dye could be degraded successfully by using N-doped ZnO under visible light. In comparative study, we found that the N-doped $\mathrm{ZnO}$ has shown six times enhanced photocatalytic activity than pure $\mathrm{ZnO}$.

\section{References}

[1] Ahmad, M., Ahmad, E., Zhang, Y.W., Khalid, N.R., Xu, J.F., Ullah, M. and Hong, Z.L. (2013) Preparation of Highly Efficient Al-Doped ZnO Photocatalyst by Combustion Synthesis. Current Applied Physics, 13, 697-704. http://dx.doi.org/10.1016/j.cap.2012.11.008

[2] Zhong, J.B., Li, J.Z., Xiao, Z.H., Hu, W., Zhou, X.B. and Zheng, X.W. (2013) Fabrication of Erbium-Doped SphericalLike ZnO Hierarchical Nanostructures with Enhanced Visible Light-Driven Photocatalytic Activity. Materials Letters, 91, 1-4. http://dx.doi.org/10.1016/j.matlet.2012.09.049

[3] Kamath, P.V., Huehn, R. and Nicolaesscu, R.A. (2002) A Sense and Shoot Approach for Photocatalytic Degradation of Organic Contaminants in Water. Journal of Physical Chemistry B, 106, 788-794. http://dx.doi.org/10.1021/jp013602t

[4] Lin, B.X., Fu, Z.-X. and Jia, Y.-B. (2001) Green Luminescent Center in Undoped Zinc Oxide Films Deposited on Silicon Substrates. Applied Physics Letters, 79, 943-945. http://dx.doi.org/10.1063/1.1394173

[5] Kothari, S., Ameta, P. and Ameta, R. (2007) Photocatalytic Bleaching of Evans Blue over ZnO Particulate System. Indian Journal of Chemistry, 46A, 432-435.

[6] Fabiyi, M.E. and Skelton, R.L. (2000) Photocatalytic Mineralization of Methylene Blue Using Buoyant TiO ${ }_{2}-\mathrm{Coated}$ Polystyrene Beads. Journal of Photochemistry and Photobiology, 132A, 121-128. http://dx.doi.org/10.1016/S1010-6030(99)00250-6

[7] Ameta, R., Vardia, J., Punjabi, P.B. and Ameta, S.C. (2006) Use of Semiconductor Iron(III) Oxides in Photocatalytic Bleaching of Some Dye. Indian Journal of Chemical Technology, 13, 114-118.

[8] Punjabi, P.B., Ameta, R., Vyas, R. and Kothari, S. (2005) Photoreduction of Congo Red by Ascorbic Acid and EDTA over Cadmium Sulphide as Photocatalyst. Indian Journal of Chemistry, 44A, 2266-2269.

[9] Benjamin, S., Vaya, D., Punjabi, P.B. and Ameta, S.C. (2011) Enhancing Photocatalytic Activity of Zinc Oxide by Coating with Some Natural Pigments. Arabian Journal of Chemistry, 4, 205-209. http://dx.doi.org/10.1016/j.arabjc.2010.06.038

[10] Egzar, H.K., Mashkour, M.S. and Jude, A.M. (2013) Study the Photodegradation of Aniline Blue in Aqueous Phase by Using Different Photocatalysts. Asian Transactions on Basic \& Applied Sciences, 3, 2221-4291.

[11] Hachem, C., Bocquillon, F., Zahraa, O. and Bouchy, M. (2001) Decolourisation of Textile Industry Wastewater by the Photocatalytic Degradation Process. Dyes and Pigments, 49, 117-125. http://dx.doi.org/10.1016/S0143-7208(01)00014-6

[12] Pare, B., Singh, P. and Jannalgadda, S.B. (2009) Artificial Light Assisted Photocatalytic Degradation of Lissamine Fast Yellow Dye in ZnO Suspension in Slurry Batch Reactor. Indian Journal of Chemistry, 48A, 1364-1369.

[13] Vyas, R., Swarnkar, H. and Ameta, S.C. (2005) The Photocatalytic Bleaching of Eosin Using ZnO: Effect of Surface Charge. Chemical and Environmental Research, 14, 53-58.

[14] Ameta, R., Punjabi, P.B. and Ameta, S.C. (2011) Photodegradation of Naphthol Green B in Presence of Semiconducting Antimony Trisulphide. Journal of the Serbian Chemical Society, 7, 1049-1055. http://dx.doi.org/10.2298/JSC100425082A

[15] Attia, A.J. (2008) Photocatalytic Iodometry over Naked and Sensitized Zinc Oxide. National Journal of Chemistry, 32, 599-609.

[16] Habibi, M.H. and Askari, E. (2011) Photocatalytic Degradation of an Azo Textile Dye with Manganese-Doped ZnO Nanoparticles Coated on Glass. Iranian Journal of Catalysis, 1, 41-44.

[17] Ahmad, M., Ahmed, E., Zhang, Y., Khalid, N.R., Xu, J., Ullah, M. and Hong, Z. (2013) Preparation of Highly Efficient Al-Doped ZnO Photocatalyst by Combustion Synthesis. Current Applied Physics, 13, 697-704. http://dx.doi.org/10.1016/j.cap.2012.11.008

[18] Peng, F., Zhu, H., Wang, H. and Yu, H. (2007) Preparation of Ag-Sensitized ZnO and Its Photocatalytic Performance under Simulated Solar Light. Korean Journal of Chemical Engineering, 24, 1022-1026. http://dx.doi.org/10.1007/s11814-007-0114-7 
[19] Samaele, N., Amornpitoksuk, P. and Suwanboon, S. (2010) Effect of pH on the Morphology and Optical Properties of Modified ZnO Particles by SDS via a Precipitation Method. Powder Technology, 203, 243-247. http://dx.doi.org/10.1016/j.powtec.2010.05.014

[20] Zheng, M. and Wu, J. (2009) One-Step Synthesis of Nitrogen-Doped ZnO Nanocrystallites and Their Properties. Applied Surface Science, 255, 5656-5661. http://dx.doi.org/10.1016/j.apsusc.2008.10.091

[21] Maensiri, S., Laoki, P. and Promarak, V. (2006) Synthesis and Optical Properties of Nanocrystalline ZnO Powders by a Simple Method Using Zinc Acetate Dehydrate and Poly(Vinyl Pyrrolidine). Journal of Crystal Growth, 289, 102-106. http://dx.doi.org/10.1016/j.jcrysgro.2005.10.145

[22] Bhatta, K.D., Sawant, D.N., Pinjari, D.V., Pandit, A.V. and Bhange, B.M. (2012) One Pot Green Synthesis of Nanosized Zinc Oxide by Sonochemical Method. Materials Letters, 77, 93-95. http://dx.doi.org/10.1016/j.matlet.2012.03.012

[23] Zamari, R., Zakaria, A., Ahangar, H.A., Darroudi, M., Zak, A. and Drummen, G.P.C. (2012) Aqueous Starch as a Stabilizer in Zinc Oxide Nanoparticle Synthesis via Laser Ablation. Journal of Alloys and Compounds, 516, 41-48. http://dx.doi.org/10.1016/j.jallcom.2011.11.118

[24] Sankara, R.B., Venkatramana, R.S., Koteeswara, R.N. and Pramoda, K. (2013) Synthesis, Structural, Optical Properties and Antibacterial Activity of Co-Doped (Ag, Co) ZnO Nanoparticles. Research Journal of Material Sciences, 1, 11-23.

[25] Seguel, G.V., Rivas, B.L. and Novas, C. (2005) Polymeric Ligand-Metal Acetate Interactions. Spectroscopic Study and Semi-Empirical Calculations. Journal of Alloys and Compounds, 50, 401-406.

http://dx.doi.org/10.1016/j.jallcom.2011.11.118 